\title{
Is Urodynamic Study an Essential Step in Preoperative Evaluation of Women with Pelvic Organ Prolapse with Urinary Tract
} Original Dysfunction: Prospective Comparative Study

\section{Article}

\author{
Mervat A. Elsersy
}

Department of Obstetrics and Gynecology, Faculty of Medicine, Alexandria University, Egypt

\begin{abstract}
Aim: Pelvic organ prolapse (POP) is commonly associated with lower urinary tract dysfunction The preoperative urodynamics as a standard investigation for urinary incontinence (UI) has been a subject of debate. We aimed to compare the clinical impact of urodynamics versus office clinical evaluation only before surgical management of POP.

Study Design: prospective comparative study.

Patients and Methods: 60 women in Shatby Maternity hospital with (POP) and lower urinary tract dysfunction have been thoroughly evaluated by history, examination and standardized questionnaire. 30 of them group (1) were subjected to pre-operative urodynamic studies. Post-operative urological dysfunction were compared and analyzed.

Results: Urodynamic study identified urinary dysfunction in $80 \%$ of women in group 1. However in group (2), 6 patients out of $16(37.5 \%)$ had stress urinary incontinence post-surgery that was not diagnosed preoperatively. These patients were POP stage 3. In group (1); no occult stress incontinence was observed in any of the patients of this group postoperatively. Conclusions: Urological profile of patients whose surgical management of pelvic organ prolapse was planned according to urodynamics finding had been improved. So we recommend urodynamics to be an integral part of diagnostic work up of pelvic organ prolapse patients.
\end{abstract}

Key Words: Detrusor over activity, lower urinary tract dysfunction, pelvic organ prolapse, stress urinary incontinence, urodynamics

Received: 07 August 2021, Accepted: 20 October 2021

Corresponding Author: Mervat A. Elsersy, Department of Obstetrics \&Gynecology, Faculty of Medicine, Alexandria University, Egypt, Tel.: +20 1096311548, E-mail: msersy@hotmail.com

ISSN: 2090-7265, November 2021, Vol.11, No. 4

\section{INTRODUCTION}

Pelvic organ prolapse (POP) affects millions of females all over the world. Advancing women age increases the risk for POP development significantly .It is estimated that $12 \%$ increase of risk for every year increase in age ${ }^{[1]}$. The risk factors for POP are many and various. Post menopause, multiparty, obesity, smoking, chronic constipation and bad obstetric history are considered the most frequent etiological factors ${ }^{[2,3]}$. Various urinary symptoms have been associated with $\mathrm{POP}^{[4]}$. Review of the literatures shows a strong relationship between POP and urinary dysfunction ${ }^{[5]}$.

Some urinary symptoms like frequency, urgency and urge incontinence can be attributed to the pelvic organ prolapse due to descent of the bladder trigon with the anterior vaginal wall prolapse causing irritation of the bladder. Also kinking and obstruction of the urethra can secondarily induce over activity of the detrusor muscle giving a clinical picture mimicking overactive bladder syndrome. These symptoms could also be present in patients and not attributed to the prolaps $\mathrm{e}^{[6]}$.
Approximately $40 \%$ of woman who undergo prolapse surgery experience urinary incontinence postoperatively ${ }^{[7]}$. Until now, no consensus has been answered the question whether pelvic reconstruction surgery and antiincontinence procedures should be done simultaneously or not and what the order of the procedures should be ${ }^{[8]}$.

Urodynamic studies are useful tools for better understanding of the etiology of lower urinary tract dysfunction $^{[9]}$. Urodynamic tests provide objective information regarding the normal and abnormal function so are essential in the assessment and diagnosis of patients presenting with lower urinary tract dysfunction ${ }^{[10]}$.

Urodynamic investigation when added in the diagnostic work-up of women with lower urinary tract dysfunction with POP is debatable ${ }^{[11]}$. Most surgeons postulated that preoperative urodynamic studies helped to modify the surgical intervention planned and to add any additional surgical procedure needed to avoid the appearance of concealed stress urinary incontinence following the reduction of pelvic organ prolapse thereby nullifying the chance of postoperative voiding dysfunction ${ }^{[12]}$. 
This study was planned to determine the usefulness of preoperative urodynamic study in improving urologic outcome following surgery in women with pelvic organ prolapse and urinary tract dysfunction.

\section{MATERIAL AND METHODS}

This prospective randomized trial was performed in Shatby Maternity University hospital, which is considered the largest hospital in Alexandria city in Egypt offering obstetrical and gynecological services for more than three millions females. The ethics committee of the hospital approved the trial. The study was started in September 2020 and finished in December 2020

Women included are those presented to the hospital with pelvic organ prolapse associated with lower urinary tract dysfunction.

Women who were excluded were those who had previous surgery for urinary incontinence, or experienced neurological disorder such as multiple sclerosis or spinal cord injuries. Or those who had complicated medical disease that made the patient unfit for anesthesia.

60 patients, fulfilled the selection criteria were counseled and informed about the trial protocol and a written consent according to declaration of Helsinki was signed. Participants were randomly assigned following simple randomization procedures (computerized random numbers) to group (1) or group (2). Each group consisted of 30 patients. All participants had been thoroughly evaluated by history and examination. A standardized questionnaire was obtained to evaluate the symptoms of stress urinary incontinence, urge urinary incontinence and obstructive symptoms. Clinical staging of pelvic organ prolapse by POP Q Staging ${ }^{[13]}$ ultrasound examination had been also carried out to rule out any pelvic pathology. Patients had completed a 3-day bladder diary (frequency volume chart) to assist in arriving at an urodynamic diagnosis. Urinalysis was performed. Only patients allocated for group (1) were subjected to urodynamic studies before surgical intervention and then corrective procedures for POP had been done. The Urodynamic studies ${ }^{[14]}$ carried out were : uroflowmetry and cystometry. The Uroflowmetry was performed by the gravimetric method, where maximum flow rate, average flow rate, voided volume and residual urine was measured. Maximum flow rate $\leq 15 \mathrm{ml} / \mathrm{sec}$, and/or residual urine of more than $50 \mathrm{ml}$ or $10 \%$ of voided volume in a bladder filled with a minimum of $150 \mathrm{ml}$ was taken as cut off to detect abnormal voiding. Cystometric parameters which indicated normal bladder function were first desire to void between 150 and $200 \mathrm{ml}$, capacity (taken as strong desire to void) of greater than $400 \mathrm{ml}$, detrusor pressure rise on filling of less than $15 \mathrm{~mm} \mathrm{H}_{2} \mathrm{O}$ per $500 \mathrm{ml}$ infused, absence of detrusor contractions, no leakage on coughing, no significant pain on filling and finally a detrusor pressure rises on voiding (maximum voiding pressure) of less than $50 \mathrm{~cm} \mathrm{H}_{2} \mathrm{O}$, with a peak flow rate of more than $15 \mathrm{ml} / \mathrm{s}$ for a voided volume over $150 \mathrm{ml}$. Urodynamic stress incontinence was diagnosed when urethral leakage was seen with increased abdominal pressure, in the absence of detrusor contractions. Detrusor over activity was diagnosed when the patient has involuntary detrusor contractions during filling with or without leakage which may be spontaneous or provoked. All participants were followedup with same questionnaire and clinical examination after 12 weeks post operatively.

\section{RESULTS}

Statistical analysis: Data were fed to the computer and analyzed using IBM SPSS software package version 20.0. (Armonk, NY: IBM Corp). Comparisons between groups for categorical variables were assessed using Chi-square test (Fisher or Monte Carlo). Significance of the obtained results was judged at the $5 \%$ level.

The age of the women recruited in group (1) in this study was between $40-73$ years. The mean age was $61.63 \pm 7.85$. Only 2 women $(6.7 \%)$ were above 70 years, whereas 15 women $(50 \%)$ were between $50-60$ years and 7 women $(23.3 \%)$ were between $60-70$ years of age .The age of the women recruited in group (2) in this study was between $42-71$ years. The mean age was $62.63 \pm 7.96$. Only 1 woman $(3.3 \%)$ was above 70 years, whereas 14 women (46\%) were between 50-60 years and 8 women $(26.7 \%)$ were between 60-70 years of age. All women recruited in this study were multiparous and parity ranging between Para 2 and Para 6. The mean parity was $4.71 \pm 1.02$. 63.33\% .Maximum number of women $(63.3 \%)$ recruited in group (2) and $(60 \%)$ of women in group $(1)$ in this study were in stage 3 prolapse . In this study 24 women $(80 \%)$ in group (1) were postmenopausal, while in group (2), 23 women (76.7\%) were postmenopausal. Statistical analysis of data about age, parity, menopausal state and stage of pelvic organ prolapse showed no significant differences between the two studied groups (Table 1).

In the present study, in group (2): 3 women had SUI who was in stage 1 and 2 . While in group (1) the 3 patients with SUI were confirmed to have USI. And one patient out of 2 with UUI showed detrusor over activity after the urodynamic studies. In both groups, the patients with complains of SUI or mixed urinary incontinence with stage 1 POP had Trans-obturator mid- urethral sling procedure. While those with complains of SUI or mixed urinary incontinence in addition to obstructive symptoms and with stage 2 POP underwent Trans-obturator mid- urethral sling procedure and cystocele repair (Table 2 ). 
Table 1: Comparison between the two studied groups according to different parameters

\begin{tabular}{|c|c|c|c|c|}
\hline & Group I $(\mathrm{n}=30)$ & Group II $(\mathrm{n}=30)$ & $\chi^{2}$ & $p$ \\
\hline \multicolumn{5}{|l|}{ Age in years } \\
\hline $40-50$ & $6(20 \%)$ & $7(23.3 \%)$ & \multirow{4}{*}{0.659} & \multirow{4}{*}{${ }^{\mathrm{MC}} \mathrm{p}=1.000$} \\
\hline $50-60$ & $15(50 \%)$ & $14(46.7 \%)$ & & \\
\hline $60-70$ & $7(23.3 \%)$ & $8(26.7 \%)$ & & \\
\hline$>70$ & $2(6.7 \%)$ & $1(3.3 \%)$ & & \\
\hline \multicolumn{5}{|l|}{ Parity } \\
\hline 2 & $3(10 \%)$ & $2(6.7 \%)$ & \multirow{4}{*}{0.520} & \multirow{4}{*}{${ }^{\mathrm{MC}} \mathrm{p}=1.000$} \\
\hline 3 & $6(20 \%)$ & $5(16.7 \%)$ & & \\
\hline 4 & $9(30 \%)$ & $10(33.3 \%)$ & & \\
\hline 5 or more & $12(40 \%)$ & $13(43.3 \%)$ & & \\
\hline \multicolumn{5}{|l|}{ Menopausal status } \\
\hline Premenopausal & $6(20 \%)$ & $7(23.3 \%)$ & \multirow{3}{*}{0.098} & \multirow{2}{*}{0.754} \\
\hline Postmenopausal & $24(80 \%)$ & $23(76.7 \%)$ & & \\
\hline \multicolumn{4}{|l|}{ Stages of POP } & \\
\hline Stage 1 & $3(10 \%)$ & $3(10 \%)$ & \multirow{3}{*}{0.199} & \multirow{3}{*}{${ }^{\mathrm{MC}} \mathrm{p}=1.000$} \\
\hline Stage 2 & $8(26.7 \%)$ & $9(30 \%)$ & & \\
\hline Stage 3 & $19(63.3 \%)$ & $18(60 \%)$ & & \\
\hline
\end{tabular}

$\chi 2$ : Chi square test

MC: Monte Carlo

p: $p$ value for comparing between the two studied groups

Table 2: Urinary dysfunction symptoms and urodynamic finding in both study groups

\begin{tabular}{|c|c|c|c|c|c|c|}
\hline \multicolumn{3}{|c|}{ Group II $(\mathrm{n}=30)$} & \multicolumn{4}{|c|}{ Group I $(n=30)$} \\
\hline $\mathrm{N}$ & Stages of POP & Symptom & $\mathrm{N}$ & Stages of POP & Symptom & Urodynamic findings \\
\hline \multirow[t]{3}{*}{3} & Stage 1 & & 3 & Stage 1 & & \\
\hline & & $1 \mathrm{SUI}$ & & & 2 SUI & 2 USI \\
\hline & & 2 UUI & & & $1 \mathrm{UUI}$ & 1 Detrusor over activity \\
\hline \multirow[t]{6}{*}{8} & Stage 2 & & 9 & Stage 2 & & \\
\hline & & $2 \mathrm{SUI}$ & & & $1 \mathrm{SUI}$ & $1 \mathrm{USI}$ \\
\hline & & $1 \mathrm{UUI}$ & & & 2 UUI & No detrusor over activity \\
\hline & & $3 \mathrm{SUI}+\mathrm{UUI}$ & & & $3 \mathrm{SUI}+\mathrm{UUI}$ & 2 USI + detrusor over activity \\
\hline & & 2 Obstructive symptoms & & & 3 Obstructive symptoms & 1 No dysfunction \\
\hline & & & & & & 2 USI \\
\hline \multirow[t]{7}{*}{19} & Stage 3 & & 18 & Stage 3 & & \\
\hline & & $2 \mathrm{SUI}+\mathrm{UUI}$ & & & $3 \mathrm{SUI}+\mathrm{UUI}$ & 3 USI and detrusor over activity \\
\hline & & 14 Obstructive symptoms & & & 12 obstructive symptoms & 2 No dysfunction \\
\hline & & 3 Obstructive symptoms + UI & & & & 3 USI and detrusor over activity \\
\hline & & & & & & 7 obstruction only \\
\hline & & & & & 3 obstructive symptoms $+\mathrm{UI}$ & 2 Obstruction and detrusor over activity \\
\hline & & & & & & $1 \mathrm{USI}$ \\
\hline
\end{tabular}


As regards women with stage 3 POP, in group 2: The 14 women who had stage 3 POP who complained of obstructive symptoms only underwent vaginal hysterectomy and cystocele repair. While the remaining five patients with stage 3 POP in addition to urinary incontinence underwent vaginal hysterectomy and anterior colporrhaphy and bladder neck buttressing (Kelly' plication).

Women in group 1 with stage 3 POP and due urodynamic studies which were done for all patients of the group, Urodynamic studies diagnosed 7 patients with UDS. So addition of bladder neck buttressing (Kelly' plication) to the vaginal hysterectomy and cystocele repair for correction of SUI. (Table 2)

Comparison of the post-operative urinary dysfunction symptoms in both study groups revealed that: in group (2), there were 6 out of 16 patients, still had stress incontinence postoperatively, because urodynamic studies were not done to the patients of group (2), while in group (1), obstructive symptoms and SUI got completely relieved postoperatively (Table 3 ). $\mathrm{P}=0.024$. All women complained of urge incontinence had no improvement for UUI postoperatively. (Table 3 )

Table 3: Post-operative urinary dysfunction symptoms in both study groups

\begin{tabular}{|c|c|c|c|c|c|}
\hline \multirow{2}{*}{ Symptom } & \multicolumn{2}{|c|}{ Group I $(\mathrm{n}=30)$} & \multicolumn{2}{|c|}{ Group II $(\mathrm{n}=30)$} & \multirow{2}{*}{$p 1$} \\
\hline & Pre-Operative & Post-Operative & Pre-Operative & Post-Operative & \\
\hline Obstructive & $15(50 \%)$ & $0(0 \%)$ & $16(53.3 \%)$ & $6(20 \%)$ & $0.024^{*}$ \\
\hline SUI & $3(10 \%)$ & $0(0 \%)$ & $3(10 \%)$ & $0(0 \%)$ & - \\
\hline Urge urinary incontinence & $3(10 \%)$ & $3(10 \%)$ & $3(10 \%)$ & $3(10 \%)$ & 1.000 \\
\hline Mixed urinary incontinence & $5(16.7 \%)$ & $3(10 \%)$ & $6(20 \%)$ & $1(3.3 \%)$ & 0.612 \\
\hline Obstructive \& urinary incontinence & $3(10 \%)$ & $0(0 \%)$ & $3(10 \%)$ & $0(0 \%)$ & - \\
\hline
\end{tabular}

p1: $p$ value for Chi square test (FE: Fisher Exact) for comparing between the two studied groups in post-operative

\section{DISCUSSION}

In this study, the age of the women recruited in group (1) was between 40-73years. The mean age was 61.63 \pm 7.85 . Only 2 women $(6.7 \%)$ were above 70 years, whereas 15 women $(50 \%)$ were between 50-60 years and 7 women $(23.3 \%)$ were between $60-70$ years of age .The age of the women recruited in group (2) in this study was between $42-71$ years. The mean age was $62.63 \pm 7.96$. Only 1 woman $(3.3 \%)$ was above 70 years, whereas 14 women $(46 \%)$ were between $50-60$ years and 8 women $(26.7 \%)$ were between 60-70 years of age .the majority of women with uterovaginal prolapse was in age group of 50-60 years. And it is widely observed that the incidence of utero-vaginal prolapse is increasing with advancing woman age $\mathrm{e}^{[3,15]}$.

Repeat vaginal child birth predisposed to prolapse as observed in this study and other studies ${ }^{[16,17]}$. All women recruited in this study were multiparous and parity ranging between Para 2 and Para 6 . The mean parity was $4.71 \pm 1.02 .63 .33 \%$.Maximum number of women $(63.3 \%)$ recruited in group (1) and (60\%) of women in group (2) in this study were in stage 3 prolapse.

In this study 24 women $(80 \%)$ in group (1) were postmenopausal, while in group (2), 23 women (76.7\%) were postmenopausal. This observation confirmed that post-menopausal estrogen deficiency and subsequently collagen defect predisposed women for POP. Also Mothes, A. R. et al concluded that $>/=10$ years since menopause were independent risk factors for pelvic organ prolapse ${ }^{[18]}$.
In this study in group (2): 3 patients were in stage 1 one of them had stress incontinence and 2 complained of urge incontinence while in group (1) there were also 3 women diagnosed to have stage 1 POP , 2 of them diagnosed to have urodynamic stress incontinence and one patient had detrusor over activity .

In group (1);9 women were diagnosed to have stage 2 pop , 2 out 3 patients who had obstructive symptoms were further diagnosed by urodynamics to have UDS, so they were treated by Trans-obturator mid- urethral sling procedure in addition to cystocele repair. Also in group (1), 18 patients were diagnosed to have sage 3 POP. Urodynamic studies diagnosed 4 women to have hidden stress incontinence. And an additional bladder neck buttressing (Kelly' plication) to the vaginal hysterectomy, i.e. that surgical management was modified in $6(20 \%)$ patients .On the other hand, urodynamic studies were not done to the patients in group 2, so no addition procedure was added in any of the patients with obstructive symptoms. These observations are consistent with the results concluded by. Al Mousa, R. T et $a l^{[10]}$. Asfour, V. et al also concluded that pre-surgical evaluation of patients with prolapse should be completed with urodynamics, due to the high proportion presumably "asymptomatic" patients ${ }^{[19]}$.

In group (1) postoperative follow up revealed complete disappearance of SUI , and no occult stress incontinence was observed in any of the patients of this group. This is attributed to the urodynamic evaluation pre surgery and an additional corrective surgical procedure which was 
performed in such patients. This matches what Ovtcharenko, N. et al had concluded that UDS testing may be useful to rule in occult stress urinary incontinence(OSUI), but its clinical value in surgical decision making is uncertain ${ }^{[20]}$.

However in group (2), 6 patients out of $16(37.5 \%)$ had stress urinary incontinence post-surgery that was not diagnosed preoperatively, these patients were POP stage 3 . It is well known that women with severe degree of prolapse rarely complain of stress urinary incontinence because of urethral kinking. But, some of these women may develop such symptoms after reduction. These findings are similar to those of Fayyad A,et al who concluded that clinical evaluation and examination of patients with vaginal prolapse is often inadequate. Prolapse physical examination in a clinic setting could be different from findings under anesthesia. This can affect the operation to repair the prolapse $\mathrm{e}^{[21]}$.

Many studies supported the presence of occult urinary incontinence in advanced stage of prolapse. In a study by Ducey et al who concluded that urodynamic study identified 17 (41.5\%) women with occult SUI. Postoperatively 3 $(7.3 \%)$ women reported urinary incontinence. None of the women without occult SUI on urodynamics reported postoperative $\mathrm{SU}^{\mathrm{I}[22]}$

In a study conducted by Shi-Yan Wang, the incidence of de novo SUI was 25\% (75/300). Univariate analysis showed that the ratio of lower urinary tract obstruction (LUTO) before surgery in de novo SUI group was significantly higher than the control group and that LUTO was independently associated with a greater risk of de novo SUI after pelvic floor surgery $(\mathrm{OR}=2.3,95 \%$ CI [1.2-4.6], $\mathrm{P}=0.013)^{[23]}$

Also In a study conducted by Chaikin et al on 24 women referred for evaluation of advanced degree of urogenital prolapse, they found that occult sphincteric incontinence was present in $58 \%$ of women with advanced degree of urogenital prolapse ${ }^{[24]}$.

In this study, urgency and urge incontinence persisted after surgery. This could be a transient symptom due to surgery .Lack of a longer duration follow up and postoperative urodynamics evaluation is considered limitations of this study. Also it is suggested that reconstructive pelvic surgery may affect pelvic innervation, especially autonomic nerves and explains the persistence of voiding symptoms such as frequency and urgency, post operatively in spite of the correction of the anatomical defect. These results are similar to those of Lo, T. S. et al who observed a good cure of the stress component of MUI, urodynamic investigation with its findings prior to management of MUI could have greater implications for selective patient centered counseling. Presence of DO or DOI on urodynamics resulted in poorer objective and subjective outcomes ${ }^{[25]}$

\section{CONCLUSIONS}

UDS remains a valuable diagnostic test, which provides vital information to both the surgeon and patient prior to invasive treatment, with minimal morbidity.

\section{AUTHOR CONTRIBUTION}

Dr. Mervat A. Elsersy designed and performed the study, also assisted with measurements and wrote the manuscript.

\section{ACKNOWLEDGMENT}

The author would like to thank Mr. Amgad Hamza who processed the study data, performed the statistical analysis and aided in interpreting the results. Also the author would like to thank the team of urodynamics who helped to perform the urodynamic studies of 30 patients.

\section{CONFLICT OF INTERESTS}

There are no conflicts of interest.

\section{REFERENCES}

1. American College of O, Gynecologists' Committee on Practice B-G, American Urogynecologic S. Pelvic Organ Prolapse: ACOG Practice Bulletin, Number 214. Obstet Gynecol. 2019;134(5):e126-e42.

2. Hakimi S, Aminian E, Mohammadi M, Mohammad Alizadeh S, Bastani P, Houshmandi S. Prevalence and Risk Factors of Urinary/Anal Incontinence and Pelvic Organ Prolapse in Healthy Middle-Aged Iranian Women. J Menopausal Med. 2020;26(1):24-8.

3. Yan W, Li X, Sun S, Xiang Y, Zhou Y, Zeng X, et al. [Risk factors for female pelvic organ prolapse and urinary incontinence]. Zhong Nan Da Xue Xue Bao Yi Xue Ban. 2018;43(12):1345-50.

4. Frigerio M, Manodoro S, Cola A, Palmieri S, Spelzini F, Milani R. Detrusor underactivity in pelvic organ prolapse. Int Urogynecol J. 2018;29(8):1111-6.

5. Walker GJ, Gunasekera P. Pelvic organ prolapse and incontinence in developing countries: review of prevalence and risk factors. Int Urogynecol J. 2011;22(2):127-35.

6. Cameron AP. Systematic review of lower urinary tract symptoms occurring with pelvic organ prolapse. Arab J Urol. 2019;17(1):23-9.

7. Smith TM, DeLancey JO, Fenner DE. Post-reduction stress urinary incontinence rates in posterior versus anterior pelvic organ prolapse: a secondary analysis. Int Urogynecol J. 2013;24(8):1355-60. 
8. Maher C, Feiner B, Baessler K, Schmid C. Surgical management of pelvic organ prolapse in women. Cochrane Database Syst Rev. 2013(4):CD004014.

9. Baines G, Da Silva AS, Araklitis G, Robinson D, Cardozo L. Recent advances in urodynamics in women. F1000Res. 2020;9.

10. Al Mousa RT, Al Dossary N, Hashim H. The role of urodynamics in females with lower urinary tract symptoms. Arab J Urol. 2019;17(1):2-9.

11. Lor KY, Soupashi M, Abdel-Fattah M, Mostafa A. Does pre-operative urodynamics lead to better outcomes in management of urinary incontinence in women? A linked systematic review and meta-analysis. Eur $\mathrm{J}$ Obstet Gynecol Reprod Biol. 2020;244:141-53.

12. Syan R, Dallas KB, Sohlberg E, Rogo-Gupta L, Elliott CS, Enemchukwu EA. Rates and Risk Factors for Future Stress Urinary Incontinence Surgery after Pelvic Organ Prolapse Repair in a Large Populationbased Cohort in California. Urology. 2019;123:81-6.

13. Madhu C, Swift S, Moloney-Geany S, Drake MJ. How to use the Pelvic Organ Prolapse Quantification (POP-Q) system? Neurourol Urodyn. 2018;37(S6):S39-S43.

14. Yao M, Simoes A. Urodynamic Testing and Interpretation. StatPearls. Treasure Island (FL)2020.

15. Masenga GG, Shayo BC, Rasch V. Prevalence and risk factors for pelvic organ prolapse in Kilimanjaro, Tanzania: A population based study in Tanzanian rural community. PLoS One. 2018;13(4):e0195910.

16. Hage-Fransen MAH, Wiezer M, Otto A, WiefferPlatvoet MS, Slotman MH, Nijhuis-van der Sanden $\mathrm{MWG}$, et al. Pregnancy- and obstetric-related risk factors for urinary incontinence, fecal incontinence, or pelvic organ prolapse later in life: A systematic review and meta-analysis. Acta Obstet Gynecol Scand. 2020.

17. Reimers C, Siafarikas F, Staer-Jensen J, Smastuen MC, Bo K, Ellstrom Engh M. Risk factors for anatomic pelvic organ prolapse at 6 weeks postpartum: a prospective observational study. Int Urogynecol J. 2019;30(3):477-82.

18. Mothes AR, Radosa MP, Altendorf-Hofmann A, Runnebaum IB. Risk index for pelvic organ prolapse based on established individual risk factors. Arch Gynecol Obstet. 2016;293(3):617-24.

19. Asfour V, Gargasole C, Fernando R, Digesu GG, Khullar V. Urodynamics are necessary for patients with asymptomatic pelvic organ prolapse. Neurourol Urodyn. 2018;37(8):2841-6.

20. Ovtcharenko N, Pudwell J, Harvey MA. Testing for Occult Stress Urinary Incontinence in Patients With Pelvic Organ Prolapse? Results of a Pragmatic Approach. J Obstet Gynaecol Can. 2020;42(4):420-9.

21. Fayyad A, Hill S, Gurung V, Prashar S, Smith AR. How accurate is symptomatic and clinical evaluation of prolapse prior to surgical repair? Int Urogynecol J Pelvic Floor Dysfunct. 2007;18(10):1179-83.

22. Duecy EE, Pulvino JQ, McNanley AR, Buchsbaum GM. Urodynamic prediction of occult stress urinary incontinence before vaginal surgery for advanced pelvic organ prolapse: evaluation of postoperative outcomes. Female Pelvic Med Reconstr Surg. 2010;16(4):215-7.

23. Wang SY, Cao TT, Wang RZ, Yang X, Sun XL, Wang JL. Incidence and Risk Factors of De novo Stress Urinary Incontinence after Pelvic Floor Reconstruction: A Nested Case-control Study. Chinese medical journal. 2017;130(6):678-83.

24. Chaikin DC, Groutz A, Blaivas JG. Predicting the need for anti-incontinence surgery in continent women undergoing repair of severe urogenital prolapse. J Urol. 2000;163(2):531-4.

25. Lo TS, Tan YL, Pue LB, Chua S, Wu MP, Hsieh WC. Outcomes of urodynamic mixed urinary incontinence and urodynamic stress incontinence with urgency after mid-urethral sling surgery. Int Urogynecol J. 2020;31(9):1949-57. 